\title{
Globe
}

Revue internationale d'études québécoises

\section{Le vingtième siècle des femmes}

\section{Chantal Maillé et Chantal Savoie}

Volume 3, numéro 2, 2000

Le vingtième siècle québécois des femmes

URI : https://id.erudit.org/iderudit/1000579ar

DOI : https://doi.org/10.7202/1000579ar

Aller au sommaire du numéro

Éditeur(s)

Globe, Revue internationale d'études québécoises

ISSN

1481-5869 (imprimé)

1923-8231 (numérique)

Découvrir la revue

Citer ce document

Maillé, C. \& Savoie, C. (2000). Le vingtième siècle des femmes. Globe, 3(2), 17-22. https://doi.org/10.7202/1000579ar d'utilisation que vous pouvez consulter en ligne.

https://apropos.erudit.org/fr/usagers/politique-dutilisation/ 


\section{Introduction Le vingtième siècle des femmes}

On a dit du vingtième siècle qu'il a été celui des plus horribles massacres, de la désillusion, de la mort des grands idéaux et de la fin des idéologies. Mais on ne peut passer sous silence la magistrale révolution des femmes au cours de ce même siècle, révolution de la ténacité, de la légitimité, mais aussi grand pas en avant pour l'humanité. Le vingtième siècle des femmes en a donc été un de lumières, de victoires et de connaissances. Au-delà d'acquis souvent perçus comme fragiles, et ce autant pour les femmes que pour nombre de groupes minoritaires, tous ces livres écrits sur les femmes, par des femmes, ne sauront disparaître de nos mémoires. Car le vingtième siècle des femmes a aussi été celui de l'édification d'une magnifique bibliothèque qui a eu le pouvoir de changer le cours des choses de façon irréversible. Les textes réunis dans ce numéro participent de cette gigantesque entreprise, prenant appui sur le changement de siècle comme ancrage temporel pour mieux mesurer l'étendue de cette révolution.

La recherche féministe et le développement d'une pensée sur les actions et réflexions des femmes ont généré, depuis le début des années '70, et ce tant au Québec que dans le reste du monde occidental, de nombreux textes individuels et collectifs. En outre, depuis les années' 80 , de nombreux bilans sont venus jalonner la pensée féministe, rendant compte des acquis, traquant des tendances et formulant de nouveaux objectifs. D'entrée de jeu, nous avons donc souhaité éviter l'écueil de nous livrer à l'exercice très fin de siècle de produire un nouvel aperçu de la somme des savoirs et de procéder à de nouveaux inventaires, alors que les plus récents tiennent encore la route. De là découle notre volonté de focaliser sur le changement et ses modulations. Plutôt que de livrer une somme, le présent numéro

Chantal Maillé et Chantal Savoie, «Introduction. Le vingtième siècle des femmes*, Globe. Revue internationale d'études québécoises, vol. 3, no 2, 2000. 
sur le XXe siècle des femmes au Québec a donc voulu faire porter la réflexion sur des passages.

À l'heure où les genres paraissent parfois se confondre, s'impose le constat que la vie des femmes au Québec a beaucoup changé. Nous avons donc convié les auteures de ce numéro à traquer cette dynamique du changement au cours du vingtième siècle. Elles ont collectivement et parfois individuellement fait appel à des approches pluridisciplinaires afin de mieux cerner la mesure de ces transformations et de les situer à l'intérieur d'une approche critique du changement socio-politique au Québec. Toutes les contributions que l'on pourra lire dans ce numéro portent ainsi sur différentes facettes de ces actes de présence des femmes dans le siècle: dynamiques sociales en mouvement, contributions du féminisme, redéfinition de certaines pratiques sociales, travail de création et pratiques culturelles. Elles sollicitent tour à tour l'histoire, la science politique, la sociologie, les théories littéraires et l'histoire de l'art pour mieux saisir cette dynamique du changement.

En guise d'ouverture, le texte de Diane Lamoureux ("La démocratie avec les femmes") fait le constat et l'analyse d'une mutation du paradigme démocratique dans laquelle l'action et la réflexion des femmes occupent un rôle prépondérant. En abordant la question de l'apport des femmes à la démocratie en général et à la société québécoise en particulier, Diane Lamoureux fait le pari de "rompre avec l'idée que le féminisme a été exclusivement un mouvement de femmes pour les femmes". Son analyse se déploie en deux volets complémentaires. Le premier volet rappelle le contexte et les idées majeures de deux temps forts des luttes féministes, ceux du suffragisme et de la lutte pour le droit à l'avortement. En second lieu, l'auteure pose les implications théoriques des enjeux démocratiques à l'œuvre dans les revendications féministes et les repositionne sur le grand échiquier de la quête démocratique. Sa conclusion sur le passage d'une démocratie à composante "fraternitaire" ("liberté, égalité, fraternité ") à une démocratie solidaire ("liberté, égalité solidarité ") propose de débusquer le "faux universalisme" fraternitaire pour remodeler la notion de démocratie sur des bases éthiques plus acceptables. 
À la suite du texte de Lamoureux, celui de Yolande Cohen propose une analyse de la construction politique de l'identité de genre à travers les différents discours féministes présents au cours du vingtième siècle, passant en revue l'une des luttes les plus symboliques de l'avancée des Québécoises vers la citoyenneté au cours du vingtième siècle. L'historienne met au centre de son propos la Fédération nationale Saint-Jean-Baptiste, qui participera à la lutte pour le suffrage féminin pour se réorienter par la suite vers un féminisme davantage tourné vers la revendication de mesures sociales. Elle se penche également sur les paramètres de l'action féministe de la deuxième vague, laquelle se cristallise autour de la mise sur pied de groupes comme la Fédération des femmes du Québec. Cohen porte également son regard sur les relations troubles entre le mouvement des femmes et le pouvoir politique pour se livrer à une analyse de conjoncture: que faire de la parité? Et comment repenser l'articulation entre le mouvement des femmes et la pensée souverainiste?

Le féminisme du vingtième siècle est aussi l'objet du texte de Johanne Daigle, qui étudie les multiples formes qu'emprunte la question des femmes au cours du vingtième siècle. Elle entend démontrer que la question des femmes, reformulée au gré des changements survenus dans la société québécoise, constitue l'une des plus importantes questions de société au vingtième siècle, interrogation qui persiste au nouveau siècle alors qu'émerge un questionnement sur la pertinence des identités rigides de sexe et de genre comme déterminants fondamentaux des identités.

Le texte de Chantal Maillé, pour sa part, propose de réfléchir sur la question du féminisme dans la période actuelle, faisant état des questionnements en émergence, comme l'aspect générationnel du projet féministe et la formulation de nouvelles avenues comme le postféminisme. À cette réflexion se greffe une étude des stratégies politiques du mouvement des femmes, étude qui permet de souligner la dynamique de l'organisation, du fonctionnement et des préoccupations de cette force incontournable de la société québécoise. 
Marie-Blanche Tahon s'intéresse quant à elle à la libération des femmes à partir des transformations qui se sont produites dans la famille à travers des indicateurs comme le mariage et la fécondité, marqués tous les deux par une chute importante, dramatique, diront certains. Une hypothèse guide l'ensemble de la démarche: la libération des femmes dans la modernité démocratique suppose la désassimilation de la figure de femme et de la figure de mère. Ce qui ouvre la voie à une relecture de la signification de certaines données : le désintérêt pour le mariage serait-il, de cette façon, le corollaire de l'accession des femmes au statut d'individu? Et que penser de la conjoncture dans laquelle s'exerce la maternité?

Dans une analyse de l'évolution du personnage de l'écrivaine dans la fiction écrite par des femmes au Québec, analyse qui se réclame à la fois de la réflexion de Virginia Woolf et des travaux d'André Belleau sur la représentation de l'écrivain dans le roman québécois, Isabelle Boisclair traque les interdits symboliques persistants qui jalonnent le parcours des femmes de lettres, tant fictives que réelles, depuis plus d'un siècle. Des horizons bloqués d'Angéline de Montbrun, qui ne parvient à se réaliser ni sur le plan de la conjugalité, ni de la maternité, ni de l'écriture, jusqu'au personnage de la mère lesbienne de L'Amèr de Nicole Brossard, le chemin parcouru est manifeste, et paraît proportionnel aux gains effectués au plan de l'évolution du statut civil des femmes. Subsistent toutefois, nous révèle l'auteure, des interdits, dont celui de la conciliation. $\mathrm{Si}$ l'horizon des possibles féminins en ce début de millénaire inclut la conjugalité, la maternité et l'écriture littéraire, force est de constater, soutient Boisclair, que la fiction ne permet pas encore de rêver les trois à la fois. Vivrions-nous toujours dans le paradigme symbolique de l'heure des choix?

C'est une tout autre vue sur les mutations des personnages féminins que nous donne le texte de Lucie Guillemette. Tout en faisant un rappel des différentes vagues du féminisme américain qui ont marqué le XXe siècle (égalitaire, radical, de la différence, global et postmoderne) et de leurs caractéristiques, l'auteure fait le constat de la pénétration des discours féministes dans la littérature pour l̀a jeunesse québécoise des dernières années. Au-delà de la 
démonstration du fait qu'une portion de la littérature pour la jeunesse constitue un lieu exemplaire des pratiques féministes contemporaines, l'article de Lucie Guillemette révèle le passage de la contestation du rôle de petites filles modèles au reflet de l'incrédulité postmoderne face aux discours féministes de la modernité. Les romans pour les jeunes mettant en vedette des protagonistes féminines permettent en outre de constater que les savoirs actualisés dans ces fictions débouchent sur une vision plurielle de la culture et de l'identité.

Enfin, le texte d'Édith-Anne Pageot présente une figure encore méconnue de la modernité picturale québécoise, l'artiste Jori Smith. Édith-Anne Pageot restitue aux portraits d'enfants (1930-1949) de Smith leur contexte tant pictural que social, et tisse les réseaux d'influence de l'artiste, tant en ce qui touche les grands penseurs qu'elle a pu lire (Jung), que ses fréquentations d'autres artistes et intellectuels qui ont marqué la modernité québécoise (Palardy, Pellan, Borduas, etc.). L'œuvre de Jori Smith est abordée tant du point de vue de la production que de celui de la réception, et son analyse suggère que les portraits d'enfants de Smith s'immiscent dans la tradition "décorative" du portrait tout en recelant une intensité existentielle qui s'expose en même temps qu'elle se dérobe à l'œil du spectateur. En filigrane, s'inscrivent toute une série de déviances des portraits d'enfants de Smith par rapport aux normes de son époque, tant du point de vue social que pictural, qui lui permettent de s'insérer de plain-pied dans la modernité.

La dynamique du changement est donc bel et bien le moteur de ce numéro qui veut rendre compte du XXe siècle des femmes au Québec. Changement de paradigme démocratique, relecture des moments historiques charnières, mouvance du féminisme, émergence de nouveaux modèles familiaux, arrimage entre la pratique et la théorie féministe, itinéraire réel et fictionnel vers le statut d'écrivaine, passages vers la modernité, les textes qui suivent jettent des regards éclairants sur le thème proposé et constituent une véritable petite phénoménologie du changement. Ils témoignent en outre de la 
fertilité du champ des études féministes, de sa capacité à se renouveler et à interagir avec les autres discours de la connaissance pour donner prise sur le réel.

\author{
Chantal MAILLÉ \\ Institut Simone de Beauvoir \\ Université Concordia
}

Chantal SAVOIE

Centre de recherche en littérature québécoise

Université Laval

Chantal Maillé et Chantal Savoie, "Introduction. Le vingtième siècle des femmes", Globe. Revue intemationale d'études québécoises, vol. 3, no 2, 2000. 